\title{
Inclusion of poly-aromatic hydrocarbon (PAH) molecules in a functionalized layered double hydroxide
}

\author{
L MOHANAMBE and S VASUDEVAN* \\ Department of Inorganic and Physical Chemistry, Indian Institute of Science, Bangalore 560012 \\ e-mail: svipc@ipc.iisc.ernet.in
}

\begin{abstract}
The internal surface of an $\mathrm{Mg}-\mathrm{Al}$ layered double hydroxide has been functionalized by anchoring carboxy-methyl derivatized $\beta$-cyclodextrin cavities to the gallery walls. Neutral polyaromatic hydrocarbon $(\mathrm{PAH})$ molecules have been included within the functionalized solid by driving the hydrophobic aromatic molecules from a polar solvent into the less polar interior of the anchored cyclodextrin cavities by a partitioning process. The optical (absorption and emission) properties of the PAH molecules included within the functionalized $\mathrm{Mg}-\mathrm{Al}$ layered double hydroxide solid are similar to that of dilute solutions of the PAH in non-polar solvents. The unique feature of these hybrid materials is that they are thermally stable over a wide temperature range with their emission properties practically unaltered.
\end{abstract}

Keywords. Layered double hydroxide; polyaromatic hydrocarbon molecules; thermal; emission properties.

\section{Introduction}

Inorganic layered solids in which guest species can access interlamellar space via the intercalation reaction offer a unique route to the design of new hybrids that combine the functionality and properties of host and guest at the molecular level. In a majority of these solids, intercalation is driven either by oxidation-reduction, acid-base or ion-exchange reactions. The interaction between host and guest is coulombic, with the guest species compensating for the charge deficit, either positive or negative, of the inorganic layer. Typical examples of these solids are the phyllosilicate clays, the layered double hydroxides, the divalent metal thiophosphates and metal (IV) phosphates and phosphonates. ${ }^{1,2}$ The subsequent host-guest chemistry of these intercalated solids is restricted to exchange of the interlamellar charged species for other ions and, to a limited extent, adsorption of polar molecules, e.g. crown ethers ${ }^{3}$ and polyethylene oxide, ${ }^{4,5}$ through ion-dipole interactions. It is, therefore, not possible to directly insert, by intercalation, neutral non-polar molecules e.g. poly-nuclear aromatic hydrocarbons (PAH), within these layered inorganic solids.

The host-guest chemistry of these solids can, however, is extended to include non-polar and poorly

Dedicated to Prof J Gopalakrishnan on his 62nd birthday

*For correspondence water-soluble molecules by appropriate functionalization of the internal surface of the solid. Anchoring of long chain surfactant molecules to the walls of the galleries is one of the well-established strategies to solubilize neutral organic molecules within an inorganic solid. ${ }^{6-9}$ Certain structural arrangements of the anchored surfactant, like the intercalated bilayer can, in fact, act as membrane mimics allowing for the incorporation of bio-molecules like cholesterol within the hydrophobic interior of the bilayer. ${ }^{10}$

Host structures are, of course, not limited to inorganic solids, a variety of organic hosts are known, the most well known of which are the crown ethers, cyclodextrins, calixarenes and spherands. ${ }^{11}$ These molecules, which are soluble in aqueous and organic solvents, can act as hosts for a variety of neutral organic molecules. In principle, if the two host structures, the layered inorganic solid and the organic host, can be integrated, a new family of host structure can be envisaged. Indeed, such organic-inorganic hybrid structures have been realized; modified cyclodextrins have been successfully intercalated in montmorillonite clays, ${ }^{12}$ zirconium phosphates ${ }^{13}$ and layered double hydroxides ${ }^{14,15}$ to create a new generation of host structures. Cyclodextrins, herein abbreviated as CDs, are cyclic oligomers of $d$-glucopyranose $\left(\mathrm{C}_{6} \mathrm{H}_{10} \mathrm{O}\right)$ with cylindrical hydrophobic cavities into which a variety of small molecules may be introduced. The solubilization of hydrophobic molecules like aromatic hydrocarbons in aqueous media by cyclodex- 
trins is well known and have been extensively studied. ${ }^{16}$ For PAH molecules with $\beta$-cyclodextrin, the commonly encountered stoichiometry is the $1: 1$ complex although other stoichiometries like $2: 2$ have also been reported for naphthalene and pyrene. ${ }^{17}$

Layered double hydroxides (LDH), the so-called anionic clays, consists of positively charged brucitelike layers and interlamellar exchangeable anions. ${ }^{18}$ Hydrotalcites are layered double hydroxides with the chemical composition $\left[\mathrm{Mg}_{1-x} \mathrm{Al}_{x}(\mathrm{OH})_{2}\right]^{x+}\left[\mathrm{A}^{n}\right]_{x / n}$. $m \mathrm{H}_{2} \mathrm{O}$ (Mg-Al-LDH) that consist of positively charged layers constructed from edge sharing $\mathrm{Mg}(\mathrm{OH})_{6}$ and $\mathrm{Al}(\mathrm{OH})_{6}$ octahedra. $^{19-22}$ The positive charge of the layers is compensated for by interlayer anions that are usually hydrated and can be exchanged for other inorganic or organic anions. They have been used as catalysts and catalyst precursors, sorbents and scavengers for halogens and weak ac$\operatorname{ids}^{23-27}$ and more recently for storing and delivering biologically active materials. ${ }^{28,29}$ The guest species, however, have, of necessity, to be anions for charge neutrality to be preserved and as a consequence, the host-guest chemistry of the LDH's is limited to ionexchange reactions. However, when the internal surface of an $\mathrm{Mg}-\mathrm{Al} \mathrm{LDH}$ is functionalized by anchoring $\beta$-cyclodextrin cavities to the gallery walls (figure $1)$, it is possible to insert neutral organometallic ${ }^{30}$ and aromatic hydrocarbon ${ }^{31,32}$ molecules within the inorganic solid as well as adsorb iodine from vapour as well as from non-polar solvents. ${ }^{33}$ Insertion occurs by the inclusion of the non-polar guest molecules within the hydrophobic interior of the anchored cyclodextrin cavities. We show here that this novel hybrid combines the functionality of the organic guest with the mechanical and thermal robustness of the inorganic solid.

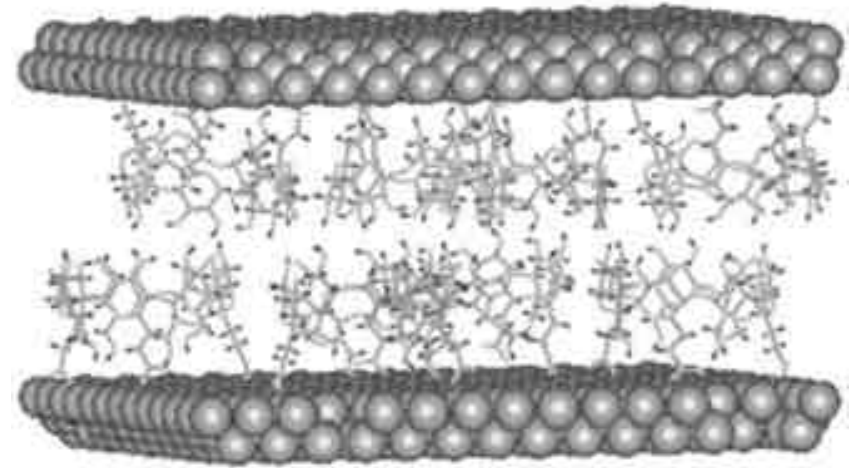

Figure 1. A model representing the arrangement of CMCD molecules within the galleries of $\mathrm{Mg}-\mathrm{Al} \mathrm{LDH}$.

\section{Experimental}

\subsection{Preparation and characterization}

$\mathrm{Mg}_{1-x} \mathrm{Al}_{x}(\mathrm{OH})_{2}\left(\mathrm{NO}_{3}\right)_{x}\left[\mathrm{Mg}-\mathrm{Al} \mathrm{LDH}-\mathrm{NO}_{3}\right]$ was prepared by co-precipitation, by dropwise addition of known volumes of aqueous $\mathrm{Mg}\left(\mathrm{NO}_{3}\right)_{2}(0.04 \mathrm{M})$ and $\mathrm{Al}\left(\mathrm{NO}_{3}\right)_{3}(0.02 \mathrm{M})$ into $\mathrm{NaOH}$ solution at a constant $\mathrm{pH}$ of 8 , under $\mathrm{N}_{2}$ atmosphere, following the procedure reported by Meyn et al. ${ }^{34}$ The resulting white precipitate was aged for $24 \mathrm{~h}$ prior to washing with de-carbonated water. The anchoring of $\beta$-cyclodextrin cavities within the $\mathrm{Mg}-\mathrm{Al} \mathrm{LDH}$ was achieved by ion-exchanging the $\mathrm{NO}_{3}$ ions in $\mathrm{Mg}_{1-x} \mathrm{Al}_{x}$ $(\mathrm{OH})_{2}\left(\mathrm{NO}_{3}\right)_{x}$ with methylcarboxylate derivatized $\beta$ cyclodextrin anions. The sodium salt of carboxymethyl $\beta$-cyclodextrin, $\mathrm{C}_{42} \mathrm{H}_{70-n} \mathrm{O}_{35}\left(\mathrm{CH}_{3} \mathrm{COONa}\right)_{n}$ (CMCD) was obtained from Cerestar Company (Hammond, In, USA). The average number of carboxylate groups per $\beta$-CMCD molecule, as established by $\mathrm{pH}$ titrations, is $3 \cdot 8$.

The ion-exchange intercalation of $\beta$-CMCD in the LDH was effected following the procedure of ref. [15]. $\mathrm{Mg}-\mathrm{Al} \mathrm{LDH}-\mathrm{NO}_{3}(100 \mathrm{mg})$ was added to $10 \mathrm{ml}$ of $10 \mathrm{mM}$ of aqueous $\beta$-CMCD solution at $65^{\circ} \mathrm{C}$ and stirred for $24 \mathrm{~h}$. Completion of the intercalation of the $\beta$-CMCD was confirmed by the absence of $00 l$ reflections with a basal spacing of $8.9 \AA$ and the appearance of a new set of $00 l$ reflections with a basal spacing of $24.5 \AA$ as determined from the powder Xray diffraction patterns. The $\beta$-CMCD stoichiometry in the LDH was established from CHN elemental analysis $(\mathrm{C} \%=18 \cdot 9, \mathrm{H} \%=5.06)$ and also from the concentration of the un-exchanged $\beta$-CMCD remaining in the reactant solution. $\mathrm{Mg} / \mathrm{Al}$ ratios in the $\mathrm{LDH}$ were determined by inductively coupled plasma spectroscopy (Jobin Yvon JY24). The composition of the starting $\mathrm{Mg}-\mathrm{Al} \mathrm{LDH}_{-} \mathrm{NO}_{3}$ was $\mathrm{Mg}_{0.7} \mathrm{Al}_{0 \cdot 3}$ $(\mathrm{OH})_{2}\left(\mathrm{NO}_{3}\right)_{0.3}$ and of $\mathrm{Mg}-\mathrm{Al}$ LDH-CMCD was $\mathrm{Mg}_{0.7} \mathrm{Al}_{0.3}(\mathrm{OH})_{2}(\mathrm{CMCD})_{0.073}$.

Benzene, naphthalene, anthracene, pyrene and phenanthrene were the poly-aromatic hydrocarbons (PAHs) inserted as guest molecules in the functionalized $\mathrm{Mg}-\mathrm{Al} \mathrm{LDH}-\mathrm{CMCD}$. Inclusion was effected by sorption from either a saturated aqueous solution or a methanol-water solution of the PAH. In a typical sorption experiment, $2 \mathrm{mg}$ of $\mathrm{Mg}-\mathrm{Al} \mathrm{LDH}-\mathrm{CMCD}$ was allowed to equilibrate with $10 \mathrm{ml}$ of aqueous PAH solution of known concentration for a period of 3 days at room temperature. Adsorption isotherms for the inclusion of naphthalene were obtained by 
determining the concentration of included naphthalene as the difference in the concentration of naphthalene in the aqueous (or methanol-water) solution before and after equilibration. The concentration of naphthalene in solution was obtained by monitoring the absorbance at $\lambda \sim 276 \mathrm{~nm}$ by $\mathrm{UV}-$ visible spectroscopy.

\subsection{Measurement techniques}

Powder X-ray diffraction patterns of $\mathrm{Mg}-\mathrm{Al} \mathrm{LDH}-$ $\mathrm{NO}_{3}, \mathrm{Mg}-\mathrm{Al} \mathrm{LDH}-\mathrm{CMCD}$ and $\mathrm{Mg}-\mathrm{Al}$ LDH-CMCD (PAH) were recorded on a Shimadzu XD-D1 X-ray diffractometer using $\mathrm{CuK}_{\alpha}$ radiation of $\lambda 1.54 \AA$. The samples were mounted by pressing the powders on a glass plate and the data were collected at a scan speed of $2^{\circ} 2 \theta / \mathrm{min}$. CHN analysis was performed on a CHNS (CARLO ERBA) elemental analyzer. FTIR spectra were recorded as $\mathrm{KBr}$ pellets on a Bruker IFS55 spectrometer operating at $4 \mathrm{~cm}^{-1}$ resolution. FT-Raman spectra were recorded on a Bruker IFS FT-Raman spectrometer using an Nd:YAG $(\lambda=$ $1.064 \mathrm{~nm}$ ) laser for excitation. Spectra were recorded at a resolution of $4 \mathrm{~cm}^{-1}$ with an unpolarised beam using an $\mathrm{Al}$ sample holder. Laser power was kept at $150 \mathrm{mw}$. Fluorescence spectra were recorded on a Perkin-Elmer LS50B model, with excitation and emission slit-widths of $5-10 \mathrm{~nm}$ and a scan speed of $60 \mathrm{~nm} / \mathrm{min}$. For variable temperature measurements, a CTI-Cryogenics closed cycle cryostat was used. Sample temperatures could be varied from 40 to $500 \mathrm{~K}$. TGA was recorded on a Perkin-Elmer-PyrisDiamond thermo gravimetric/differential thermal analyzer (TG/DTA) system in flowing air.

\section{Results}

\subsection{Carboxymethyl $\beta$-cyclodextrin functionalized $M g-A l L D H$}

The ion-exchange intercalation of $\beta-\mathrm{CMCD}$, with an average degree of carboxymethyl substitutions of 3.8 per cyclodextrin molecule, in $\mathrm{Mg}_{0.7} \mathrm{Al}_{0.3}(\mathrm{OH})_{2}$ $\left(\mathrm{NO}_{3}\right)_{0.3}$ occurs with an increase in the interlayer lattice spacing from $8.9 \AA$ to $24.6 \AA$ (figure $2 \mathrm{a}$ ) that corresponds to a lattice expansion of $19.8 \AA \AA^{15}$ The intercalated $\mathrm{Mg}-\mathrm{Al} \mathrm{LDH}-\mathrm{CMCD}$ is stable on exposure to the atmosphere as well as moisture and the anchored $\beta$-CMCDs are no longer exchangeable, e.g. with carbonate ions. Thermo-gravimetric analysis (TGA) of $\mathrm{Mg}-\mathrm{Al} \mathrm{LDH}-\mathrm{CMCD}$ (figure 3) shows a two-step weight loss. There is a $\sim 8 \%$, weight loss at $\sim 80^{\circ} \mathrm{C}$ that probably corresponds to water sticking to the exterior of the crystallites and a gradual weight loss $(\sim 7 \%)$ between $80^{\circ} \mathrm{C}$ and $250^{\circ} \mathrm{C}$ possibly be due to interlamellar water. The second weight loss at $\sim 300^{\circ} \mathrm{C}$ is due to the decomposition of the intercalated carboxymethyl $\beta$-cyclodextrin. The $\mathrm{Na}$ salt of CMCD decomposes at $270^{\circ} \mathrm{C}$.

The ${ }^{13} \mathrm{C}$ CP-MAS NMR of the Mg-Al LDH-CMCD and that of the sodium salt of $\beta$-CMCD are shown in figure $2 b$ along with the assignments for the resonances. The positions of the resonances in the two compounds are identical indicating that the integrity of the cyclodextrin cavity is preserved on intercalation. This was further confirmed by the fact that the positions of the infrared and Raman bands of the two compounds were identical (figure 4). To summarize, the NMR and vibrational spectra indicate that the structural integrity of the $\beta$-cyclodextrin cavity is preserved on intercalation in the $\mathrm{Mg}-\mathrm{Al}$ LDH. The absence of any significant change in the positions of the vibrational modes of the glucopyranose units as well as in their linkages in the infrared and Raman spectra suggests that the geometry of the intercalated $\beta$-cyclodextrin cavity is essentially the same as that outside the layers.

The observed lattice expansion and stoichiometry can be accounted for by a perpendicular bilayer arrangement of the cyclodextrin molecules in the galleries, with the axis of the cyclodextrin cavities parallel to the interlayer normal. ${ }^{15}$ The $\beta$-cyclodextrin molecule may be considered a truncated cone with an approximate torus thickness of $7.8 \AA$. The outer diameter of the wider end of the cone is $15.4 \AA$ while that of the narrower end is $7.8 \AA$. The carboxymethyl groups are attached by substitution of the primary hydroxyl groups located at the narrower end of the truncated cone. ${ }^{11}$ Molecular modelling shows that the presence of the carboxymethyl groups increases the effective torus thickness by $1.46 \AA$. The perpendicular bilayer arrangement would therefore result in an interlayer expansion of $18.52 \AA$, which is close to the experimental value of $19 \cdot 8 \AA$.

\subsection{Polarity of the anchored carboxymethyl- $\beta$ - cyclodextrin}

In order to establish the hydrophobicity of the microenvironment within the anchored cyclodextrin cavities, the fluorescence spectra of pyrene included within the $\mathrm{Mg}-\mathrm{Al} \mathrm{LDH}-\mathrm{CMCD}$ was examined. The 

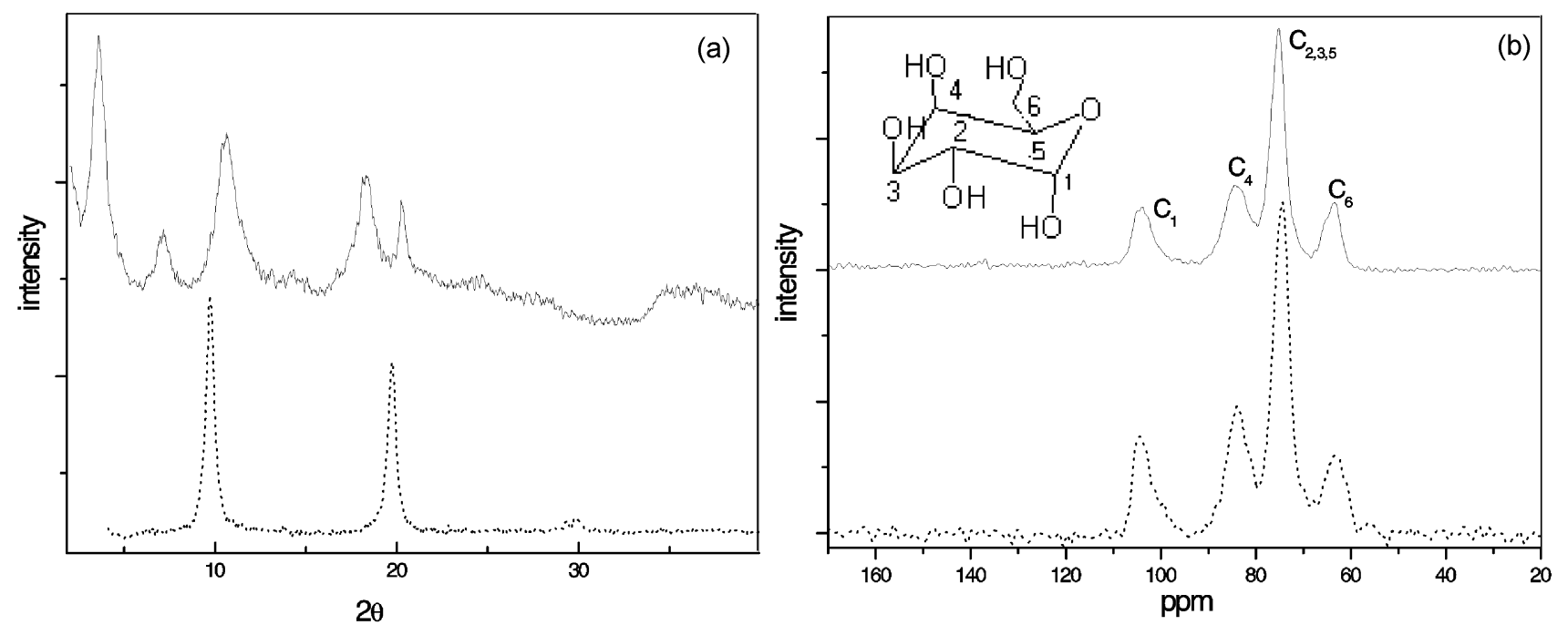

Figure 2. (a) X-ray diffraction pattern and (b) ${ }^{13} \mathrm{C}$ CP-MAS NMR of $\mathrm{Mg}-\mathrm{Al} \mathrm{LDH}-\mathrm{CMCD}$ and $\mathrm{Mg}-\mathrm{Al} \mathrm{LDH}_{-} \mathrm{NO}$ (dotted line).

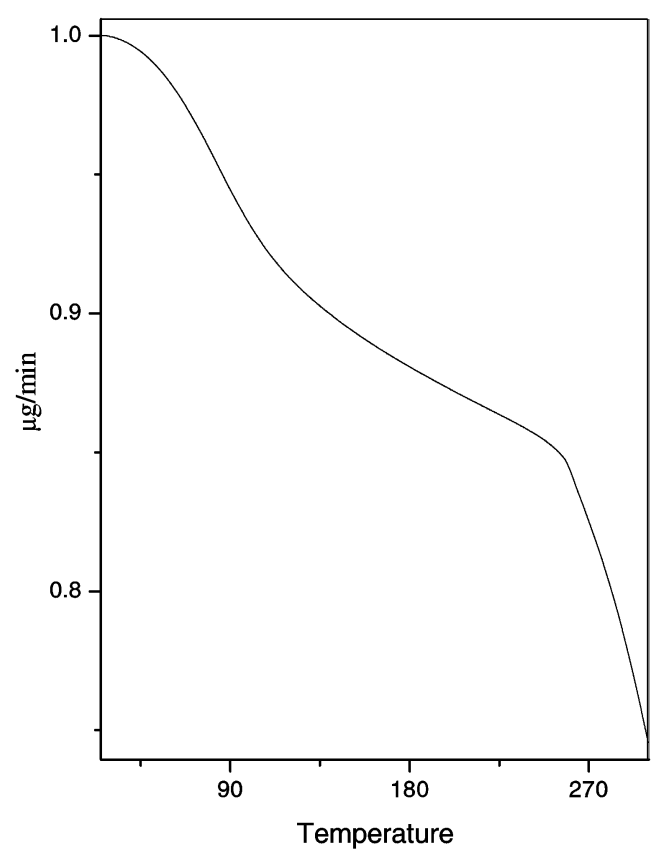

Figure 3. Thermo-gravimetric analysis of $\mathrm{Mg}-\mathrm{Al} \mathrm{LDH}-$ CMCD.

fluorescence of pyrene has been widely used to establish the polarity of the medium in which it is present. ${ }^{35}$ In polar solvents, there is an enhancement in the intensity of the symmetry forbidden $(0-0)$ band (Ham effect). ${ }^{36}$ The relative intensity of the first, $I_{\mathrm{I}}$, and third, $I_{\mathrm{III}}$, vibronic bands of the first singlet emission $\left(S_{1} \rightarrow S_{0}\right)$ correlates reasonably well with solvent polarity. The intensity ratio of pyrene, $I_{\mathrm{I}} / I_{\mathrm{III}}$, varies, typically, from 0.6 in non-polar solvents, like hexane, to 1.95 in polar solvents like dimethyl sulphoxide. ${ }^{37}$

The fluorescence spectrum of pyrene included within the $\mathrm{Mg}-\mathrm{Al} \mathrm{LDH}-\mathrm{CMCD}$ by sorption from an aqueous solution $(\sim 0.8 \mu \mathrm{M})$ of pyrene is shown as an inset in figure 5 . The emission spectra were obtained by excitation within the pyrene absorption band at $335 \mathrm{~nm}$. The average value of the intensity ratio of $I_{\mathrm{I}} / I_{\mathrm{III}}\left(I_{370 \mathrm{~nm}} / I_{390 \mathrm{~nm}}\right)$ is 0.92 . In order to place this value on a relative polarity scale, the fluorescence spectra of pyrene in different solvents were recorded and the values of the intensity ratio of $I_{\mathrm{I}} / I_{\mathrm{III}}$ plotted as a function of the dielectric constant of the solvent (figure 5). It may be seen from figure 5 that the polarity within the cavities of the anchored cyclodextrins lie in between that of methanol and 1:1 methanol-water mixture. The value of the dielectric constant $\sim 55$ is similar to that reported for $\beta$-cyclodextrin cavities. ${ }^{17}$ The data of figure 5 suggest that it may be possible to drive a hydrophobic guest molecules into anchored cyclodextrin cavities from polar solvents, those that lie to the right of the $\mathrm{Mg}-\mathrm{Al}$ LDH-CMCD in figure 5.

\subsection{Partitioning equilibria}

The poly-aromatic hydrocarbons naphthalene, ${ }^{31}$ anthracene, ${ }^{32}$ pyrene and phenenathrene, as well as benzene (for reference) were partitioned into the $\mathrm{Mg}-\mathrm{Al} \mathrm{LDH}-\mathrm{CMCD}$ from aqueous solutions. The inclusion of the PAHs in the $\mathrm{Mg}-\mathrm{Al} \mathrm{LDH}-\mathrm{CMCD}$ 

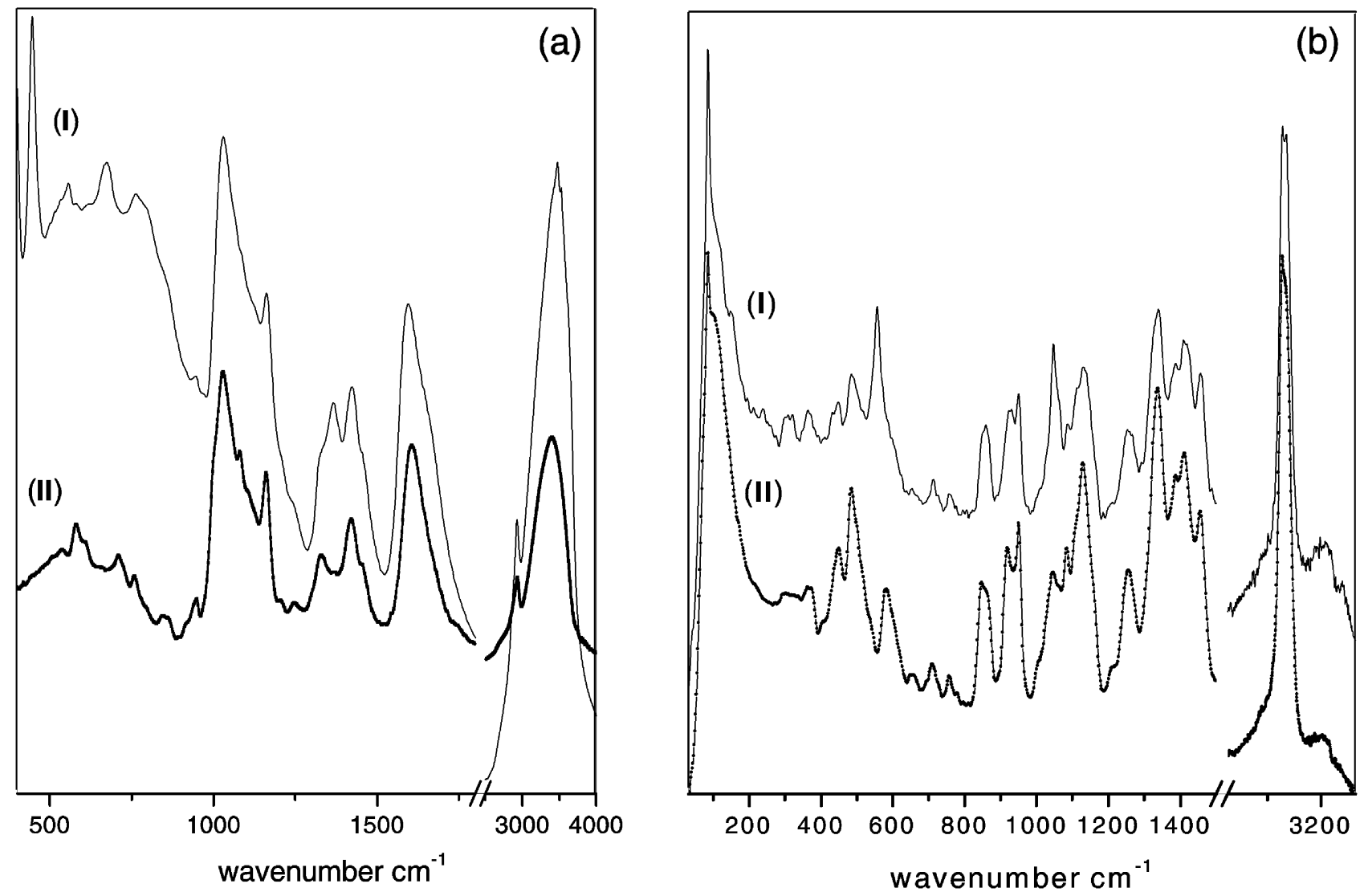

Figure 4. (a) Infrared spectra and (b) Raman spectra of (I) Mg-Al LDH-CMCD and (II) Na salt of CMCD.

does not lead to any change in the inter-layer spacing; the X-ray diffraction patterns were identical to that in figure 2a. Insertion of PAHs does not lead to any change in the composition of the host $\mathrm{Mg}-\mathrm{Al} \mathrm{LDH}-$ CMCD. Thermo-gravimetric measurements showed that the PAH inclusion compounds were thermally stable up to $550 \mathrm{~K}$ at which temperature the parent $\mathrm{Mg}-\mathrm{Al} \mathrm{LDH}-\mathrm{CMCD}$ decomposes. The position of the infrared and Raman vibrational modes of the intercalated cyclodextrin also show no change on inclusion of PAHs. The Raman spectra, however, show additional bands of the included PAH (figure 6 and table 1). The fact that the vibrational bands of the intercalated cyclodextrin show no significant change suggests that they may be considered as rigid hydrophobic containers for the inclusion of the PAHs.

The equilibrium uptake of naphthalene by the $\mathrm{Mg}-\mathrm{Al} \mathrm{LDH}-\mathrm{CMCD}$ from aqueous as well as solutions in three different methanol-water mixtures of differing polarity is shown in figure 7 . The amount of naphthalene included in the $\mathrm{Mg}-\mathrm{Al} \mathrm{LDH}-\mathrm{CMCD}$, expressed as the molar ratio of included naphthalene to anchored cyclodextrin cavities in the LDH (referred to as the naphthalene/CMCD mol ratio), is plotted as a function of the molar concentration of the naphthalene solution in figure 7 . The adsorption isotherms are linear with the slope proportional to the polarity of the solution. The maximum uptake is from aqueous solutions while there is practically no uptake from the 2:1 methanol-water solution, the least polar of the four solvents. The linearity of the isotherms is consistent with the idea that the sorption of naphthalene by the $\mathrm{Mg}-\mathrm{Al} \mathrm{LDH}-\mathrm{CMCD}$ is a partitioning process rather than physical adsorption. ${ }^{38}$ The slope of the isotherm, the partition coefficient, clearly indicates that the partitioning equilibria favours the less polar environment for the hydrophobic 'solute', naphthalene.

\subsection{Optical properties}

The photo-physics and luminescence of poly-aromatic hydrocarbons are one of their most significant and widely studied properties. ${ }^{39}$ We have examined 
Table 1. Raman spectral positions and assignments of naphthalene (solid), LDH-CMCD, LDH-CMCD (naphthalene) $)_{0.45}$ at room temperature and at $373 \mathrm{~K}$.

\begin{tabular}{|c|c|c|c|c|}
\hline $\begin{array}{l}\text { Naphthalene } \\
\text { (solid) } \mathrm{cm}^{-1}\end{array}$ & $\begin{array}{l}\text { LDH-CMCD } \\
\text { (naphthalene) } \\
\left(\mathrm{cm}^{-1}\right) 273 \mathrm{~K}\end{array}$ & $\begin{array}{l}\mathrm{LDH}-\mathrm{CMCD} \\
\text { (naphthalene) } \\
\left(\mathrm{cm}^{-1}\right) 373 \mathrm{~K}\end{array}$ & LDH-CMCD & Assignment \\
\hline 3056 & 3056 (br) & 3056 (br) & - & Sym. C-H stretch \\
\hline- & 2915 (br) & 2915 (br) & 2915 (br) & $\mathrm{C}-\mathrm{H}$ stretch \\
\hline 1577 (br) & 1577 (br) & 1577 (br) & - & Sym. C-C stretch \\
\hline \multirow[t]{2}{*}{1444} & 1438 (weak) & 1436 (br) & - & Sym. $\mathrm{C}-\mathrm{H}$ bending \\
\hline & 1407,1333 & 1407,1333 & 1410 (br), 1338 & $\begin{array}{l}\mathrm{C}-\mathrm{C} \text { stretch, } \mathrm{C}-\mathrm{O}-\mathrm{H} \text { bond, } \\
\mathrm{CH}_{2} \text { deformation }\end{array}$ \\
\hline \multirow[t]{2}{*}{1382} & 1379 & 1377 & - & Asym. C-C stretch \\
\hline & $1255,1130,1043$ & $1255,1130,1038$ & $1255,1130,1048$ & $\begin{array}{l}\mathrm{C}-\mathrm{O}-\mathrm{H} \text { stretch, } \mathrm{OH} \\
\text { deformation, } \mathrm{C}-\mathrm{C} \text { skeletal } \\
\text { stretch }\end{array}$ \\
\hline 1020 & 1024 & 1024 & - & Sym. C-C stretch \\
\hline- & 949,924 & 924 (broad) & 949,924 & $\begin{array}{l}\mathrm{C}-\mathrm{O}-\mathrm{C} \text { stretch of }(1 \\
\text { linkages }\end{array}$ \\
\hline \multirow[t]{2}{*}{763} & 760 & 759 & - & Skeletal sym. breathing \\
\hline & 552 & 555 & 556 & CMCD-ring vibrations \\
\hline 513 & 510 & 510 & - & Skeletal distortion \\
\hline 392 & 392 (weak, br) & 392 & - & Skeletal bending \\
\hline
\end{tabular}

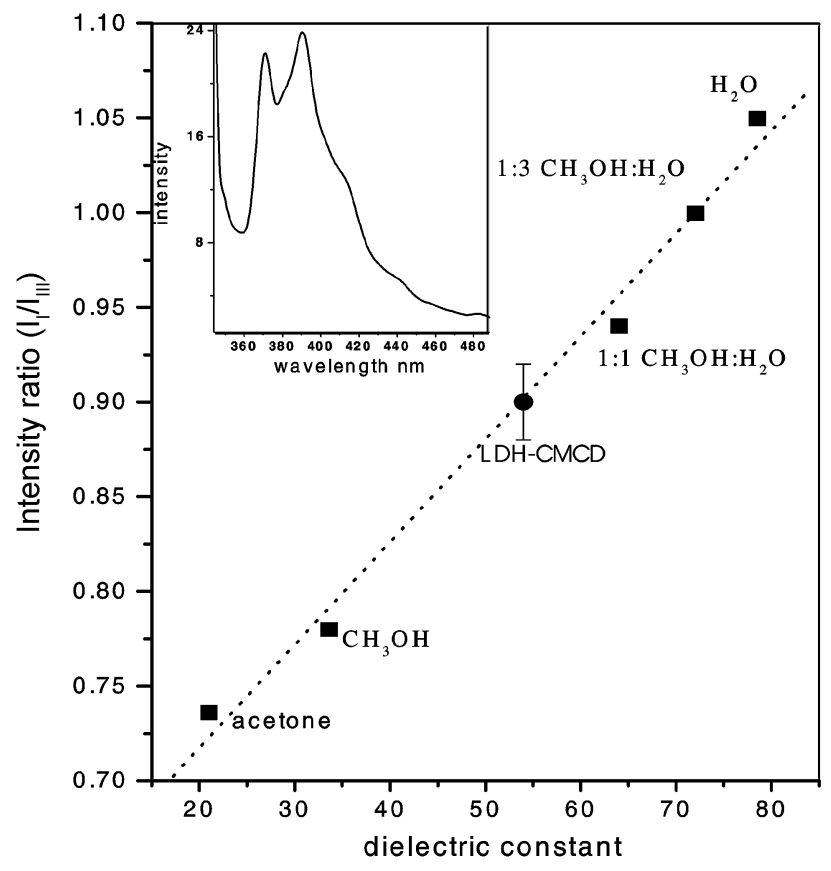

Figure 5. The variation of the intensity ratio of the first and third vibronic bands in the fluorescence spectra of pyrene, $I_{\mathrm{I}} / I_{\mathrm{III}}$, as function of solvent polarity. The bar indicates the range of $I_{\mathrm{I}} / I_{\mathrm{III}}$ ratios observed for pyrene included within Mg-Al LDH-CMCD. The inset shows the fluorescence spectra of pyrene included within $\mathrm{Mg}-\mathrm{Al}$ LDH-CMCD.

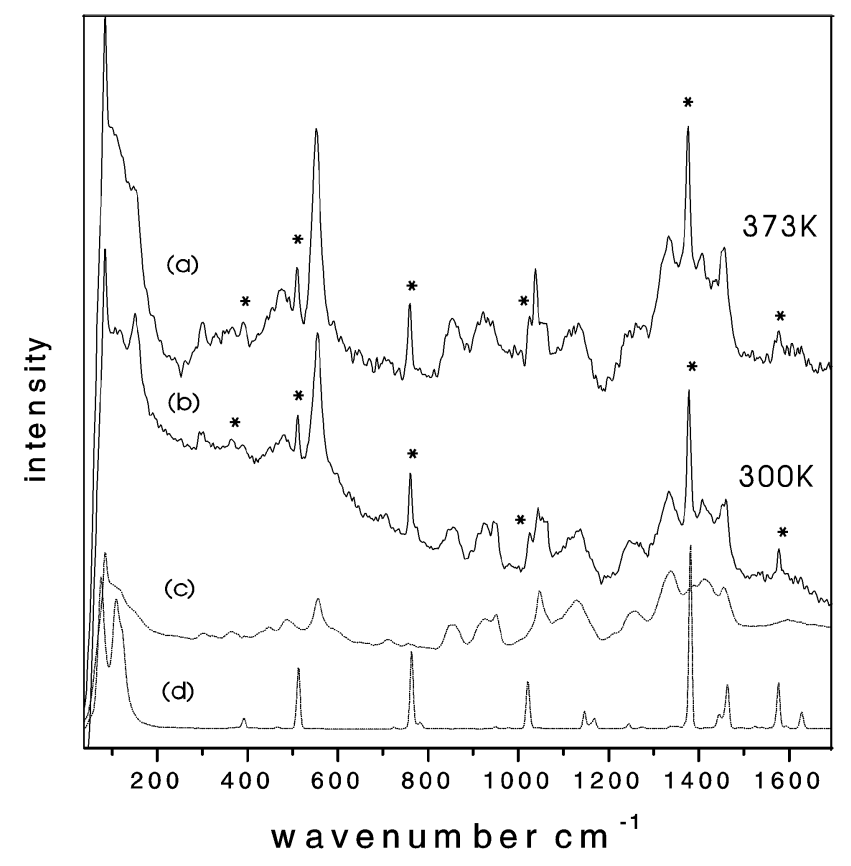

Figure 6. Raman spectra of $\mathrm{Mg}-\mathrm{Al}$ LDH-CMCD (naphthalene) at (a) $300 \mathrm{~K}$ and (b) $373 \mathrm{~K}$. The bands due to the included naphthalene are indicated. For comparison the spectra of (c) Mg-Al LDH-CMCD and (d) naphthalene solid are also shown. 
the optical - absorption and fluorescence - spectra of these aromatic molecules included within the anchored cyclodextrin cavities of the $\mathrm{Mg}-\mathrm{Al} \mathrm{LDH}-$ CMCD. The room temperature fluorescence excitation and emission spectra of naphthalene, anthracene, pyrene and phenanthrene included in the functionalized LDH are shown in figures $8 \mathrm{a}-\mathrm{d}$ and the band positions and assignments tabulated in table 2 . In all the systems studied, the spectra are highly structured with the vibronic bands reasonably well resolved. The quality and resolution of features in the spectra, recorded in the solid state (figure 8), are comparable to the reported spectra of dilute solutions of the PAHs in non-polar solvents. ${ }^{39}$ The absorption and excitation spectra are similar but features are less resolved in the former due to spectral broadening.

The fluorescence excitation and emission spectra of naphthalene included in $\mathrm{Mg}-\mathrm{Al} \mathrm{LDH}-\mathrm{CMCD}$ are shown in figure $8 \mathrm{a}$. The spectral features at 222 and $287 \mathrm{~nm}$ in the excitation spectra are due to the $S_{0} \rightarrow$

Table 2. Fluorescence excitation and emission spectral band positions and their assignments of $\mathrm{Mg}-\mathrm{Al} \mathrm{LDH}-$ $\mathrm{CMCD}(\mathrm{PAH})$.

\begin{tabular}{|c|c|c|c|}
\hline Sample & $\begin{array}{c}\text { Excitation } \\
\text { spectra }(\mathrm{nm})\end{array}$ & $\begin{array}{c}\text { Emission } \\
\text { spectra }(\mathrm{nm})\end{array}$ & Assignments \\
\hline LDH-CMCD & 300 & & $S 0-S 1$ \\
\hline \multirow[t]{8}{*}{ (naphthalene) } & 310 & & $(0-0)$ \\
\hline & 267 & & $S 0-S 2$ \\
\hline & 276 & & \\
\hline & 287 & & $(0-0)$ \\
\hline & 222 & & $S 0-S 3(0-0)$ \\
\hline & & 322 & $S 1-S 0$ \\
\hline & & 332 & \\
\hline & & 346 & $(0-0)$ \\
\hline \multirow{6}{*}{$\begin{array}{l}\text { LDH-CMCD } \\
\text { (anthracene) }\end{array}$} & 377 & & $S 0-S 1(0-0)$ \\
\hline & 252 & & $S 0-S 2(0-0)$ \\
\hline & & 377 & $S 1-S 0(0-0)$ \\
\hline & & 399 & \\
\hline & & 421 & \\
\hline & & 300 & $S 2-S 0$ \\
\hline \multirow{7}{*}{$\begin{array}{l}\text { LDH-CMCD } \\
\text { (pyrene) }\end{array}$} & 337 & & $S 0-S 2(0-0)$ \\
\hline & 322 & & \\
\hline & 272 & & $S 0-S 3(0-0)$ \\
\hline & 239 & & $S 0-S 4(0-0)$ \\
\hline & & 370 & $S 1-S 0(0-0)$ \\
\hline & & 384 & \\
\hline & & 390 & \\
\hline LDH-CMCD & 294 & & $S 0-S 2(0-0)$ \\
\hline \multirow[t]{4}{*}{ (phenanthrene) } & 254 & & $S 0-S 3(0-0)$ \\
\hline & & 348 & $S 1-S 0(0-0)$ \\
\hline & & 363 & \\
\hline & & 378 & \\
\hline
\end{tabular}

$S_{3}$ and $S_{0} \rightarrow S_{2}$ transitions respectively, while the bands at 267 and $276 \mathrm{~nm}$ are the vibronic states associated with the $S_{0} \rightarrow S_{2}$ transition. The weak absorptions at 300 and $310 \mathrm{~nm}$ are transitions from the ground state to the first excited state $\left(S_{0} \rightarrow S_{1}\right)$. The corresponding emission $\left(S_{1} \rightarrow S_{0}\right)$ in the fluorescence spectra appears at $322(0-0), 332(1-0)$ and $346(2-0) \mathrm{nm}$. The positions of the bands in both the excitation and emission spectra of the $\mathrm{Mg}-\mathrm{Al} \mathrm{LDH}-$ $\mathrm{CMCD}$ (naphthalene) are identical to those for dilute solutions of naphthalene in hexane. ${ }^{39}$

The excitation spectra of anthracene in the $\mathrm{Mg}-\mathrm{Al}$ LDH-CMCD shows the $S_{0} \rightarrow S_{2}$ and $S_{0} \rightarrow S_{1}$ transition at 252 and $377 \mathrm{~nm}$, respectively with the vibronic structure being well resolved for the latter (Figure $8 \mathrm{~b}$ ). The corresponding $S_{1} \rightarrow S_{0}$ emission (370$450 \mathrm{~nm}$ ), too, shows clearly resolved transitions associated with the vibronic states. The emission band at $300 \mathrm{~nm}$ is probably due to the $S_{2} \rightarrow S_{0}$ transition. As in the case of the included naphthalene, the positions of the bands in the excitation and emission spectra are identical to those of a dilute solution of anthracene in hexane.

The excitation and emission spectra of pyrene included within the Mg-Al LDH-CMCD are shown in figure $8 \mathrm{c}$. The spectra are similar to that of pyrene in dilute solutions and also to that of isolated pyrene- $\beta$ -

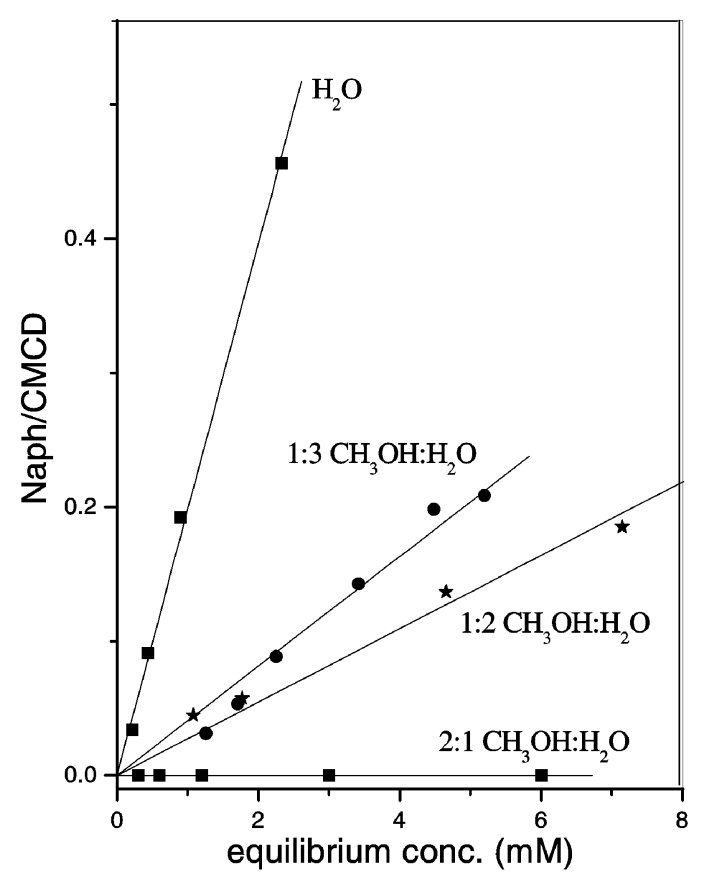

Figure 7. Equilibrium uptake of naphthalene by $\mathrm{Mg}-\mathrm{Al}$ LDH-CMCD at $298 \mathrm{~K}$ from different methanol-water mixture solutions. 

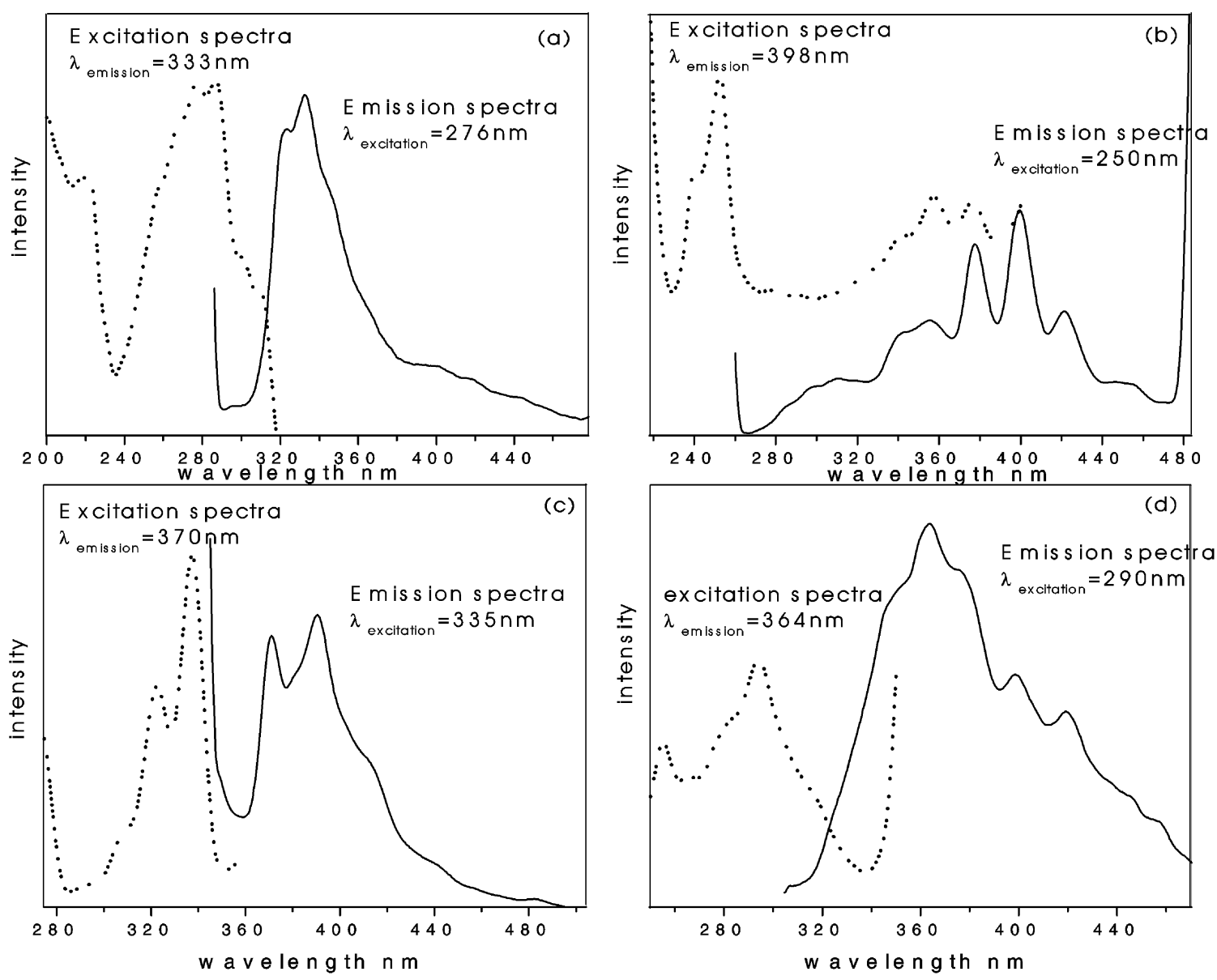

Figure 8. Excitation and emission spectra of (a) Mg-Al LDH-CMCD (naphthalene), (b) Mg-Al LDH-CMCD (anthracene), (c) Mg-Al LDH-CMCD (pyrene) and (d) Mg-Al LDH-CMCD (phenanthrene). The emission wavelength at which the excitation spectra were recorded and the excitation wavelength at which the emission spectra were recorded is indicated on each panel.

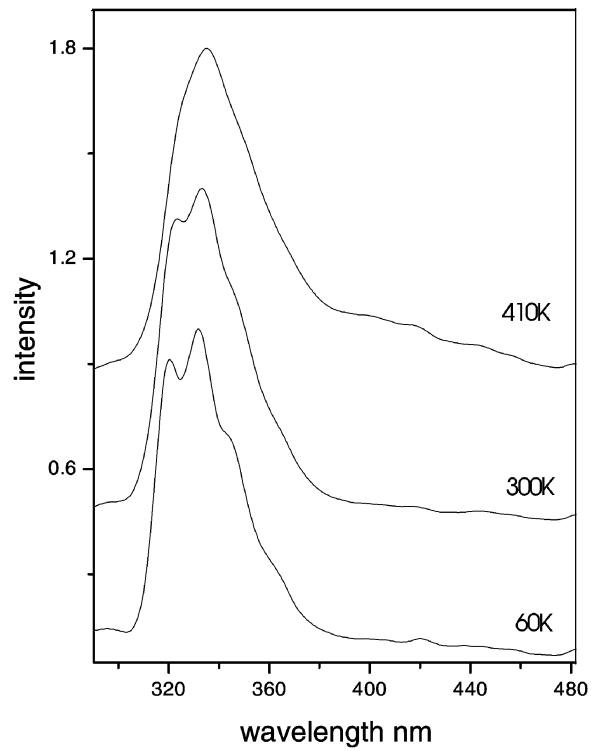

Figure 9. Fluorescence emission spectra of $\mathrm{Mg}-\mathrm{Al}$ LDH-CMCD (naphthalene) at different temperatures.
CD complexes trapped in sol-gel glasses. ${ }^{40}$ The features at 272 and $337 \mathrm{~nm}$ in the excitation spectra are the $S_{0} \rightarrow S_{3}$ and $S_{0} \rightarrow S_{2}$ transitions respectively while the shoulder at $239 \mathrm{~nm}$ is the $S_{0} \rightarrow S_{4}$ excitation. As expected, the symmetry forbidden $S_{0} \rightarrow S_{1}$ band is absent in the spectrum of the included pyrene. The symmetry selection rules also apply for phenanthrene included in the Mg-Al LDH-CMCD; the $S_{0} \rightarrow S_{1}$ is absent in the excitation spectra, while in the fluorescence spectrum, the transitions involving the higher vibrational states of the $S_{1} \rightarrow S_{0}$ emission are prominent (figure 8d). The $S_{1} \rightarrow S_{0}(0-0)$ transition is the shoulder at $347 \mathrm{~nm}$ in the fluorescence spectrum.

\subsection{Thermal stability}

The fluorescence spectra of the naphthalene included within the cyclodextrin functionalized LDH 

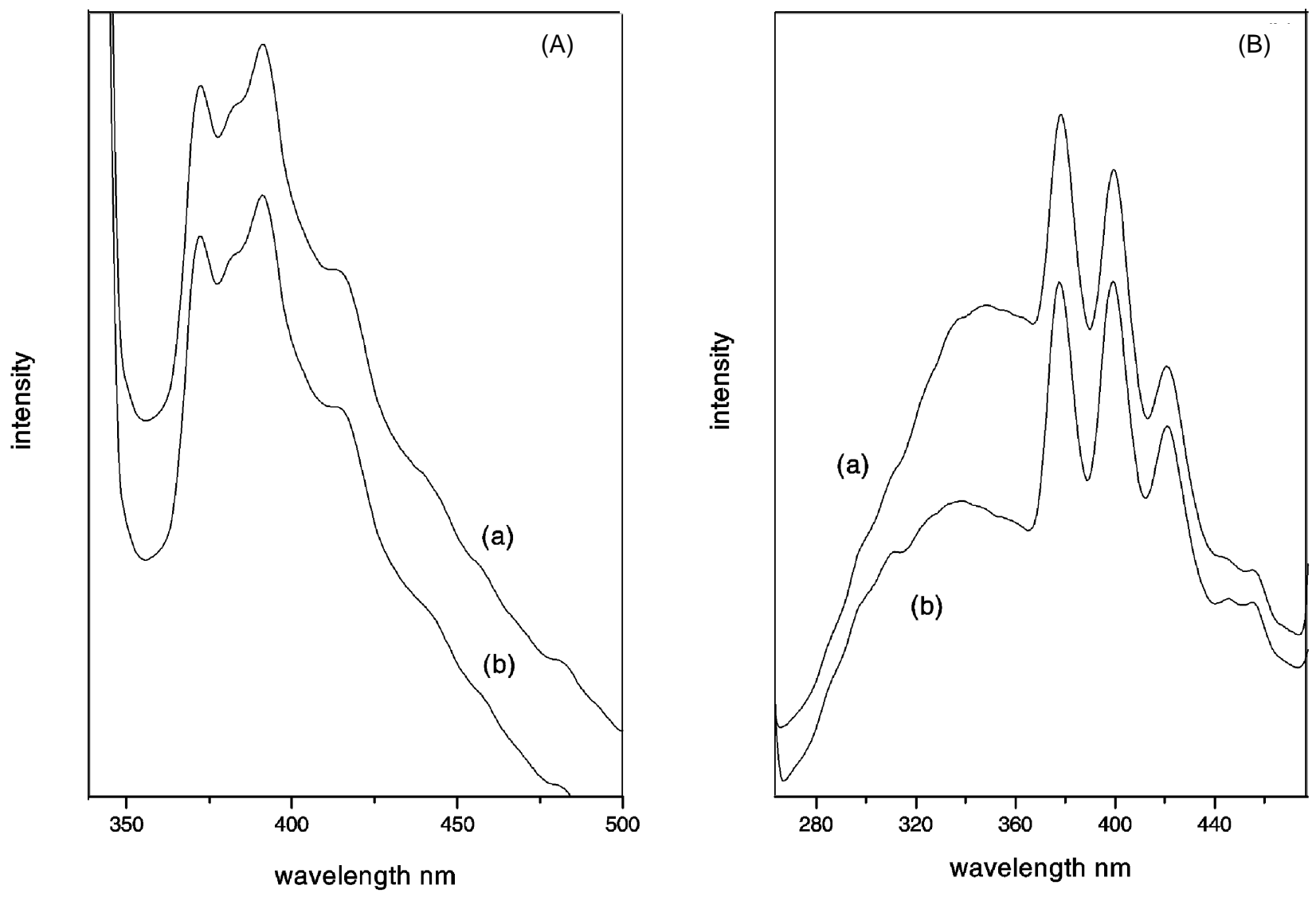

Figure 10. Emission spectra of (A) $\mathrm{Mg}-\mathrm{Al} \mathrm{LDH}-\mathrm{CMCD}$ (pyrene) and (B) $\mathrm{Mg}-\mathrm{Al} \mathrm{LDH}-\mathrm{CMCD}$ (anthracene) at room temperature before (a) and after (b) heating to $500 \mathrm{~K}$.

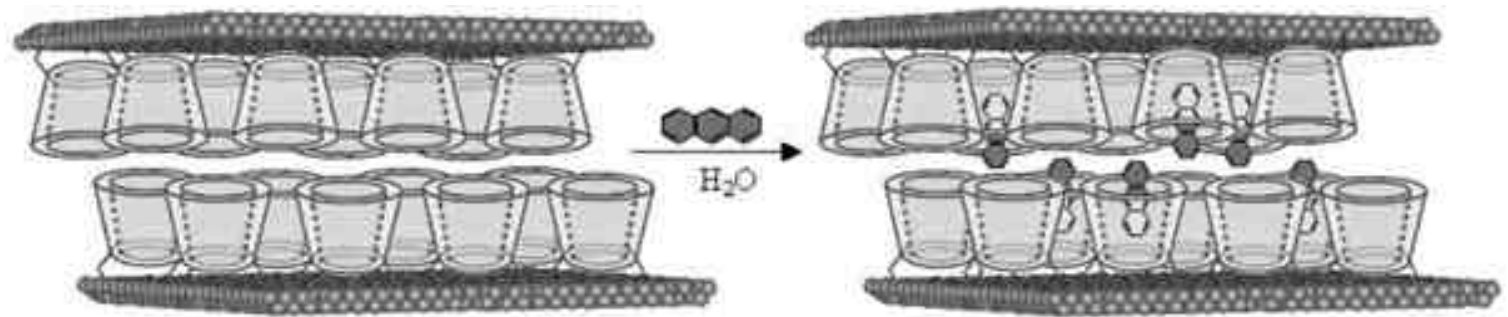

Figure 11. Cartoon illustrating the inclusion of a PAH anthracene, within the anchored cyclodextrin cavities by partitioning from a polar solvent.

solid, recorded at different temperatures is shown in figure 9. The emission corresponds to the $S_{1} \rightarrow S_{0}$ transition. The unique feature of these hybrid materials is that they are thermally stable over a wide temperature range with their emission properties practically unaltered. It may be seen that apart from changes in the relative intensities of the vibronic transitions arising from changes in the Boltzman distribution at different temperatures, the spectra are similar. The thermal robustness of these materials is clearly demonstrated from the fact that we are able to observe the emission spectra even at temperatures above those at which naphthalene solid would normally sublime $(\sim 353 \mathrm{~K})$. The $410 \mathrm{~K}$ fluorescence spectra of the $\mathrm{Mg}-\mathrm{Al} \mathrm{LDH}-\mathrm{CMCD}$ (naphthalene) clearly eliminate the possibility that the observed optical properties are due to naphthalene sticking to the exterior of the $\mathrm{Mg}-\mathrm{Al} \mathrm{LDH}-\mathrm{CMCD}$ crystallites. 
The behaviour of the other Mg-Al LDH-CMCD $(\mathrm{PAH}) \mathrm{s}$ are similar with the emission spectra remaining essentially unaltered at elevated temperatures. The $\mathrm{Mg}-\mathrm{Al} \mathrm{LDH}-\mathrm{CMCD}(\mathrm{PAH})$ can, in fact, be heated to temperatures close to the decomposition temperature $(550 \mathrm{~K})$; cooled back to room temperature and the fluorescence spectra reproduced (figure 10).

\section{Conclusions}

The internal surface of an $\mathrm{Mg}-\mathrm{Al}$ layered double hydroxide has been functionalized by anchoring carboxymethyl derivatized $\beta$-cyclodextrin cavities to the gallery walls. The structural integrity of the cyclodextrin cavity is preserved on intercalation. The fluorescence spectra of pyrene included within the functionalized $\mathrm{Mg}-\mathrm{Al} \mathrm{LDH}-\mathrm{CMCD}$ has been used to establish the hydrophobicity of the anchored cavities and the polarity, so determined, lies inbetween that of a 1:1 methanol-water mixture and pure methanol with the corresponding value of the dielectric constant around 55. Functionalization of the LDH has, therefore, resulted in the creation of hydrophobic nano-pockets within the essentially hydrophilic interlamellar space of the inorganic solid. It is shown here that neutral poly-aromatic hydrocarbons can be accommodated within these hydrophobic 'pockets'. Inclusion occurs by partitioning; the hydrophobic PAH guest molecule is driven from a polar solvent into the less polar interior of the anchored $\beta$-CD cavities (figure 11). The optical - absorption and emission - properties of the PAHs included within the functionalized $\mathrm{Mg}-\mathrm{Al} \mathrm{LDH}-$ CMCD solid are similar to that of dilute solutions of the PAH in non-polar solvents. This is not surprising since the included PAHs are prevented from aggregating by the fact that the $\beta-C D$ cavities are anchored to the gallery walls. The uniqueness of these hybrid materials is that the optical properties of dilute solutions of the PAHs are realized in the solid state. Additionally, they are thermally stable over a wide temperature range. The emission properties of the PAHs included within the $\mathrm{Mg}-\mathrm{Al} \mathrm{LDH}-\mathrm{CMCD}$ are not significantly altered even at elevated temperatures - temperatures normally at which even the $\mathrm{PAH}$ solids are not stable. In conclusion, we have demonstrated that neutral poly-aromatic hydrocarbons can be included within a cyclodextrin functionalized $\mathrm{Mg}-\mathrm{Al} \mathrm{LDH}$. The new hybrid material combines the optical properties of the aromatic organic guest with the mechanical and thermal robustness of the inorganic solid host.

\section{References}

1. Whittingham M S 1982 Intercalation chemistry (New York: Academic Press)

2. Alberti G and Costantino U 1996 Comprehensive supramolecular chemistry (Chichester: Wiley) vol 7, p. 1

3. Gluech D S, Brough A R, Mountford P and Green M L H 1993 Inorg. Chem. 321893

4. Aranda P and Hitzky R 1990 Adv. Mater. 2545

5. Jeevanandam P and Vasudevan S 1998 Chem. Mater. 101276

6. Ogawa M and Kuroda K 1997 Bull. Chem. Soc. Jpn. 702593

7. Venkataraman N V, Mohanambe L and Vasudevan S 2003 J. Mater. Chem. 13170

8. Venkataraman N V and Vasudevan S 2003 J. Phys. Chem. B107 5371

9. Wouter L and Pinnavaia T J 2001 Green Chemistry 3 10

10. Venkataraman N V and Vasudevan S 2003 J. Phys. Chem. B107 10119

11. (a) Vogtle F 1991 Supramolecular chemistry (Chichester: Wiley); (b) Steed J W and Atwood J L 2000 Supramolecular chemistry (Chichester: Wiley)

12. Kijima T, Tanaka J, Goto M and Matsui Y 1984 Nature (London) $\mathbf{3 1 0} 45$

13. Kijima T and Matsui Y 1986 Nature (London) 322 533

14. (a) Zhao H and Vance G F 1997 J. Chem. Soc., Dalton. Trans. 11 1961; (b) Zhao H and Vance G F 1998 J. Inclusion Phenom. 31 305; (c) Zhao $\mathrm{H}$ and Vance G F 1998 Clays Clay Miner. 46712

15. Mohanambe L and Vasudevan S 2005 Langmuir 21 10735

16. (a) Fujiki M, Deguchi T and Sanamesa I 1988 Bull. Chem. Soc. Jpn. 61 1163; (b) Patonay G, Shapira A, Diamond P and Warner I M 1986 J. Phys. Chem. 90 1963; (c) Shixiang G, Liansheng W, Qingguo H and Sukui H 1998 Chemosphere 371299

17. Connors K A 1996 Comprehensive supramolecular chemistry (eds) J Szejtli J and T Osa (London: Pergamon) vol 3, p. 234

18. Khan I K and Hare D O 2002 J. Mater. Chem. 12 3191

19. Constantino V R L and Pinnavaia T J 1995 Inorg. Chem. 34883

20. Miyata S 1977 Clays. Clay. Miner. 2514

21. Miyata S 1983 Clays. Clay. Miner. 31305

22. Miyata S 1975 Clays. Clay. Miner. 23369

23. De Roy A, Forano C, El Malki K and Bessi J P 1992 Expanded clays and other microporous solids (eds) M L Occelli and H E Robson (New York: Van Nostrand Reinhold) vol 2, p. 108

24. Cavani F, Trifiró F and Vaccari A 1991 Catal. Today 11173 
25. Newman S and Jones W 1998 New J. Chem. 22105

26. Vaccari A 1999 Appl. Clay Sci. 14161

27. Rives V and Ulibarri M 1999 Coord. Chem. Rev. 181 61

28. Choy J H, Kwak S Y, Park J S, Jeong Y J and Portier J 1999 J. Am. Chem. Soc. 1211399

29. Choy J H, Kwak S Y, Jeong Y J and Park J S 2000 Angew. Chem., Int. Ed. 394042

30. Mohanambe L and Vasudevan S 2005 Inorg. Chem. 442128

31. Mohanambe L and Vasudevan S 2005 J. Phys. Chem. B109 11865

32. Mohanambe L and Vasudevan S 2005 J. Phys. Chem. B109 22523
33. Mohanambe L and Vasudevan S 2004 Inorg. Chem. 436421

34. Meyn M, Beneke K and Lagaly G 1990 Inorg. Chem. 295201

35. Kalyanasundaram K and Thomas J K 1977 J. Am. Chem. Soc. 992039

36. (a) Koyanagi M 1968 J. Mol. Spectrosc. 25 273; (b) Robinson G W 1967 J. Chem. Phys. 46572

37. Valeur B 2001 Molecular fluorescence: Principles and applications (Weinheim, Berlin: Wiley-VCH Verlag)

38. Cary T C, Louis J P and Virgil H F 1979 Science 206831

39. Birks J B 1970 Photophysics of aromatic molecules (New York: John-Wiley and Sons)

40. Matsui K 1992 Langmuir 8673 